\title{
Linking bone development on the caudal aspect of the distal phalanx with lameness during life
}

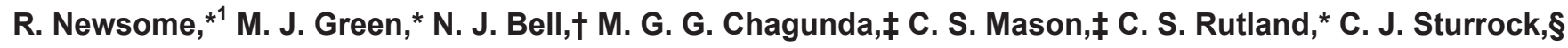 \\ H. R. Whay,\# and J. N. Huxley* \\ *School of Veterinary Medicine and Science, University of Nottingham, Sutton Bonington Campus, Sutton Bonington, Leicestershire, \\ LE12 5RD, United Kingdom \\ †Royal Veterinary College, Hawkshead Lane, North Mymms, Hertfordshire, AL9 7TA, United Kingdom \\ ¥Scotland's Rural College (SRUC), Kings Buildings, West Mains Road, Edinburgh, EH9 3JG, United Kingdom \\ $\S S c h o o l$ of Biosciences, University of Nottingham, Sutton Bonington Campus, Sutton Bonington, Leicestershire, LE12 5RD, United Kingdom \\ \#School of Veterinary Sciences, University of Bristol, Langford House, Langford, BS40 5DU, United Kingdom
}

\section{ABSTRACT}

Claw horn disruption lesions (CHDL; sole hemorrhage, sole ulcer, and white line disease) cause a large proportion of lameness in dairy cattle, yet their etiopathogenesis remains poorly understood. Untreated CHDL may be associated with damage to the internal anatomy of the foot, including to the caudal aspect of the distal phalanx upon which bone developments have been reported with age and with sole ulcers at slaughter. The primary aim of this study was to assess whether bone development was associated with poor locomotion and occurrence of CHDL during a cow's life. A retrospective cohort study imaged 282 hind claws from 72 Holstein-Friesian dairy cows culled from a research herd using X-ray micro-computed tomography ( $\mu$-CT; resolution: $0.11 \mathrm{~mm}$ ). Four measures of bone development were taken from the caudal aspect of each distal phalanx, in caudal, ventral, and dorsal directions, and combined within each claw. Cow-level variables were constructed to quantify the average bone development on all hind feet (BD-Ave) and bone development on the most severely affected claw (BD-Max). Weekly locomotion scores (1-5 scale) were available from first calving. The variables BD-Ave and BD-Max were used as outcomes in linear regression models; the explanatory variables included locomotion score during life, age, binary variables denoting lifetime occurrence of CHDL and of infectious causes of lameness, and other cow variables. Both BD-Max and BD-Ave increased with age, CHDL occurrence, and an increasing proportion of locomotion scores at which a cow was lame (score

Received August 3, 2015.

Accepted February 23, 2016.

${ }^{1}$ Corresponding author: svxrn@nottingham.ac.uk
4 or 5). The models estimated that BD-Max would be $9.8 \mathrm{~mm}$ (SE 3.9) greater in cows that had been lame at $>50 \%$ of scores within the 12 mo before slaughter (compared with cows that had been assigned no lame scores during the same period), or $7.0 \mathrm{~mm}$ (SE 2.2) greater if the cow had been treated for a CHDL during life (compared with cows that had not). Additionally, histology demonstrated that new bone development was osteoma, also termed "exostosis." Age explained much of the variation in bone development. The association between bone development and locomotion score during life is a novel finding, and bone development appears specific to CHDL. Bone development on the most severely affected foot was the best explained outcome and would seem most likely to influence locomotion score. To stop irreparable anatomical damage within the foot, early identification of CHDL and effective treatment could be critical.

Key words: dairy cow, lameness, claw horn disruption lesion, distal phalanx

\section{INTRODUCTION}

Claw horn disruption lesions (CHDL) constitute a noninfectious subset of lameness-causing diseases and include sole ulcers, sole hemorrhage, and white line disease (Offer et al., 2003; Bicalho and Oikonomou, 2013). These lesions have a high rate of reoccurrence (Enevoldsen et al., 1991; Green et al., 2014; Foditsch et al., 2016), delayed detection of lameness increases the risk of more severe lameness (Bell et al., 2009), and the risk of CHDL increases as a cow ages (Sanders et al., 2009). Given that CHDL are associated with production losses, reproductive inefficiency, and poor welfare (Sprecher et al., 1997; Dyer et al., 2007; Algers et al., 2009), preventing the disease would be ideal (Potterton et al., 2012). However, their etiopathogenesis remains 
poorly understood; better understanding of the disease process may inform targeted prevention strategies (Algers et al., 2009; Potterton et al., 2012).

Within the hoof capsule, the distal phalanx is suspended from the wall by laminar attachments and supported above the sole by the digital cushion (Lischer et al., 2002). The "typical" sole ulcer (one of the most severe manifestations of claw horn disruption) develops beneath the axial aspect of the flexor tuberosity of the distal phalanx (Rusterholz, 1920); sole hemorrhage is considered a precursor (Whay et al., 1997). Short ligaments attach the abaxial aspect of the distal phalanx to the abaxial hoof wall, whereas longer interdigital ligaments supporting the axial side of the distal phalanx allow greater depression of the axial aspect of the flexor tuberosity during foot-strike, perhaps leading to greater compression of the germinal epithelium at the sole ulcer site (Lischer et al., 2002). The digital cushion dissipates concussive forces transferred through the caudal aspect of the distal phalanx during foot-strike and loading, and it is thought to aid CHDL prevention by reducing peak forces on the germinal epithelium of the sole (Räber et al., 2004; Bicalho et al., 2009; Gard et al., 2015).

Bone developments appear on and around the flexor tuberosity with age (Tsuka et al., 2012) and have been termed "exostosis" (Maclean, 1970; Blowey et al., 2000; Lischer et al., 2002), indicating growth of new bone from the surface of a bone, or "enthesopathy" (Tsuka et al., 2012), indicating the inclusion of an enthesis (the insertion of a tendon or ligament onto bone). The new bone development may be an exacerbating factor for ulceration (Rusterholz, 1920; Maclean, 1970; Tsuka et al., 2012), and appears greater in cows with sole ulcers at slaughter (Tsuka et al., 2012), yet a link between lifetime history of lameness and lesions has not yet been demonstrated.

Our primary aim was to discern whether bone developments on the caudal aspect of the distal phalanx were associated with lameness from CHDL throughout a cow's life, and secondarily to define their structural composition.

\section{MATERIALS AND METHODS}

\section{Study Design and Hypothesis}

A retrospective cohort study investigated whether lameness and other variables recorded during life were associated with bone development on the caudal aspect of the distal phalanx at slaughter. The null hypothesis was that a lifetime history of poor locomotion or occurrence of CHDL (assessed using locomotion score or treatment data, respectively) was not associated with greater bone development on and around the caudal aspects of the distal phalanx at slaughter.

\section{Study Herd}

The study population consisted of cows culled from the Crichton Royal Herd at the SRUC Dairy Research and Innovation Centre (Dumfries, UK) between November 2013 and August 2014. The center comprised 2 units, Langhill and Acrehead, where cows were milked 3 times daily.

As heifers, all animals calved into the Langhill herd. The Langhill herd runs a long-term, $2 \times 2$ factorial design trial, genetic line $\times$ management system. Cows were between 75 and $99 \%$ pure Holstein and split into 2 genetic lines: Control and Select. Control line sires had PTA for fat plus protein yield representative of the UK average at time of breeding, whereas Select line sires had the highest available within the UK (Pryce et al., 1999). Management systems were (1) homegrown: cows were managed less intensively with access to pasture where possible (typically between April and October) and fed a high-forage diet of entirely farmgrown produce, and (2) by-product: cows were housed year round and fed a low-forage diet consisting of straw and bought-in distillery by-products, molasses, and soy (Pryce et al., 1999; Chagunda et al., 2009). Cows at Langhill were locomotion scored weekly by trained, experienced assessors following standard protocols, on a 5-point scale based on Manson and Leaver (1988). Cows given a score of 4 or 5 (defined as "obvious lameness on any leg, where behavior is affected") on a single visit or a score of 3 ("slight lameness detectable") in 2 consecutive weeks were considered lame and received veterinary treatment, as described by Randall et al. (2015). A professional foot trimmer attended both herds twice a year to trim feet deemed to be overgrown.

Acrehead is primarily a commercial unit, and locomotion score data were not routinely captured. Cows were moved from Langhill to Acrehead at the end of their fourth lactation, although they could have been moved earlier due to incidence of mastitis, poor fertility, or requirements of experimental protocols in the Langhill herd. Therefore, locomotion data immediately preceding slaughter were only available for cows that had recently been at Langhill. Culling occurred in both herds based on commercial or health and welfare grounds.

\section{Sample Collection}

The hind feet of all cows culled from either herd between the specified dates were collected postmortem at 
an abattoir, uniquely identified, and transported on ice to the University of Nottingham for storage at $-20^{\circ} \mathrm{C}$.

\section{Computed Tomography Imaging of Feet}

Feet were thawed overnight before micro-computed tomography $(\mu \mathrm{CT})$ scanning, and then packaged in pairs using radiolucent foam and containers. The device used was a cone beam X-ray micro-CT (X-ray $\mu \mathrm{CT}$ ) scanner: Phoenix v|tome|x m (GE Sensing and Inspection Technologies GmbH, Wunstorf, Germany), set at $125 \mathrm{kV}$ and $320 \mu \mathrm{A}$ (Archer et al., 2015). A 0.5-mm copper filter was placed near the X-ray tube to reduce detector saturation, and samples were oriented to minimize scatter at the site of measurement. The distances between the X-ray source and the sample and the X-ray source and the detector were 450.29 and $818.69 \mathrm{~mm}$, respectively, resulting in a magnification of $1.82 \times$ and a spatial resolution of $110 \mu \mathrm{m}$. Each scan acquired 2,160 projection images over a $360^{\circ}$ rotation of the sample using a detector exposure time of $333 \mathrm{~ms}$, integrated over 3 averaged images, resulting in a total scan time of $48 \mathrm{~min}$. Data were reconstructed using an inline median smoothing filter in datos|x software (GE Sensing), and exported in a volume file (.vgl) for image analysis using VGStudio MAX 2.2 (Volume Graphics GmbH, Heidelberg, Germany).

\section{Measurement of Bone Developments}

Image files of each foot were assessed to measure the extent of bone development extending from the caudal aspect of the distal phalanx of each claw (Figure 1a and 1b). Linear measurements were taken of the maximum extent of bone development at 4 locations, A to D, extending in the following directions: (A) plantar from the flexor tuberosity, (B) distally (toward the toe) along the base of the distal phalanx, (C) caudally from the axial aspect of the flexor tuberosity, and (D) caudally from the abaxial aspect of the flexor tuberosity. Before all measurements were taken, each claw was oriented in sagittal, transverse, and frontal cross-sectional views simultaneously following a standard protocol, to ensure landmarks and direction of measurements were consistent (Figure 1a).

Measurement A was the greatest vertical bone development from the contour of the cortical bone, on the plantar aspect of the flexor tuberosity. The caudal-most aspect of the trochlear ridge of the distal phalanx in the distal interphalangeal joint ("X" in Figure 1a and 1b) was identified as a consistent landmark that did not alter with bone development. A line drawn vertically down from $\mathrm{X}$ was visible in all views and became the origin of measurements B, C, and D. Measurement B was taken in the sagittal plane and extended horizontally from the line vertically down from $\mathrm{X}$ to the distalmost tip (toward the toe) of bone development on the plantar aspect of the distal phalanx. Measurements C and $\mathrm{D}$ were taken in the transverse plane and extended from the vertical line down from $\mathrm{X}$ to the caudal-most tip of the greatest bone development axial to and abaxial to location X, respectively (Figure 1b). Scrolling through the $\mu \mathrm{CT}$ image slices of $0.11-\mathrm{mm}$ thickness enabled identification of the greatest protrusion in each case. The height (measured vertically from location $\mathrm{X}$ to the origin of measurement A) and width (measured across the widest point) of the caudal aspect of the distal phalanx were also recorded.

\section{Statistical Analysis: Descriptive Statistics}

Associations of bone development between feet within cow and between claws within foot were explored using scatterplots and Spearman rank correlation coefficients or coefficients of determination, and compared with nonparametric Mann-Whitney U-tests.

\section{Statistical Analysis: Modeling}

To evaluate the relationship between cow lameness history and bone development, linear regression models were constructed with outcome variables describing bone development and explanatory variables describing cow factors, including age and lameness data. Two variables calculated from measurements A to D were tested individually as outcomes in a linear regression model, using ordinary least squares algorithms and a forward stepwise procedure. To obtain the 2 outcome variables, measurements A to D were summed within each claw; (1) BD-Max was the greatest individual claw value (representing the most severely affected claw), and (2) BD-Ave was the mean value across all hind claws.

Explanatory variables describing a cow's lameness history were constructed to evaluate associations between bone development and lameness, and were based on either lesion treatment or locomotion score data. For lesion treatment, binary variables denoted whether a cow had been treated for (1) a CHDL, or (2) an infectious cause of lameness, since first calving. The effect of locomotion score on bone development at slaughter was explored using descriptions of locomotion score as follows. The percentage of scores at which a cow was lame (scores 3-5) or severely lame (4-5) was calculated for lactation 1 ; lactation 2 ; the $6,12,18$, and 24 mo subsequent to first calving; and periods preceding slaughter of between 2 and 12 mo. Mean and median locomotion scores were tested during the same periods. Individual animals could only be included in a model if locomo- 
(a)
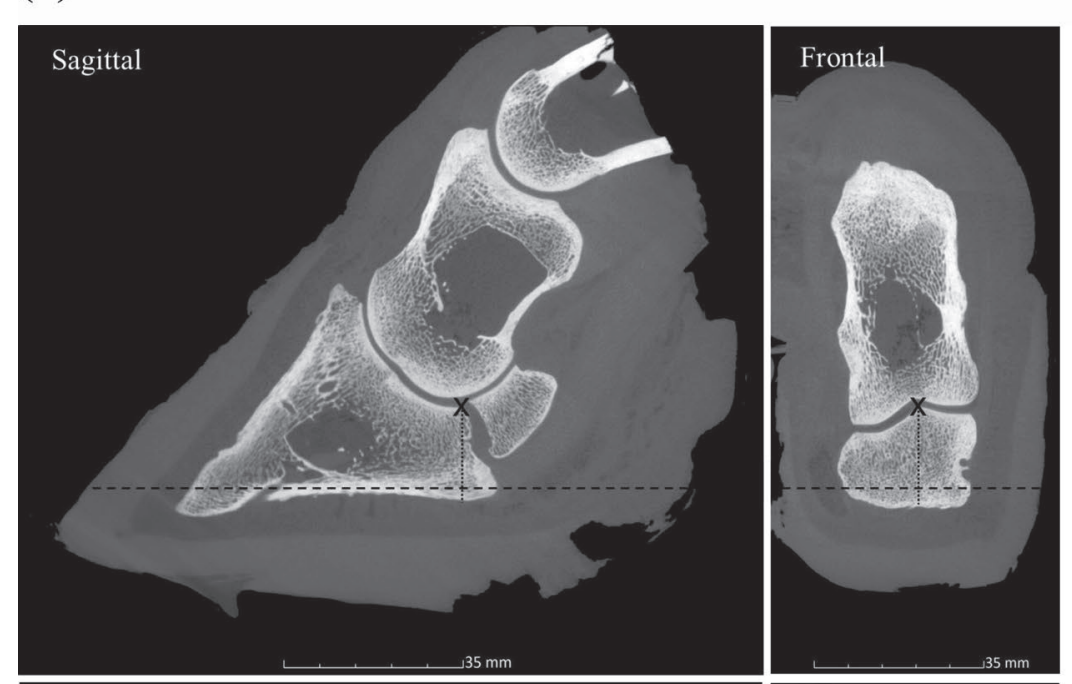

(b)
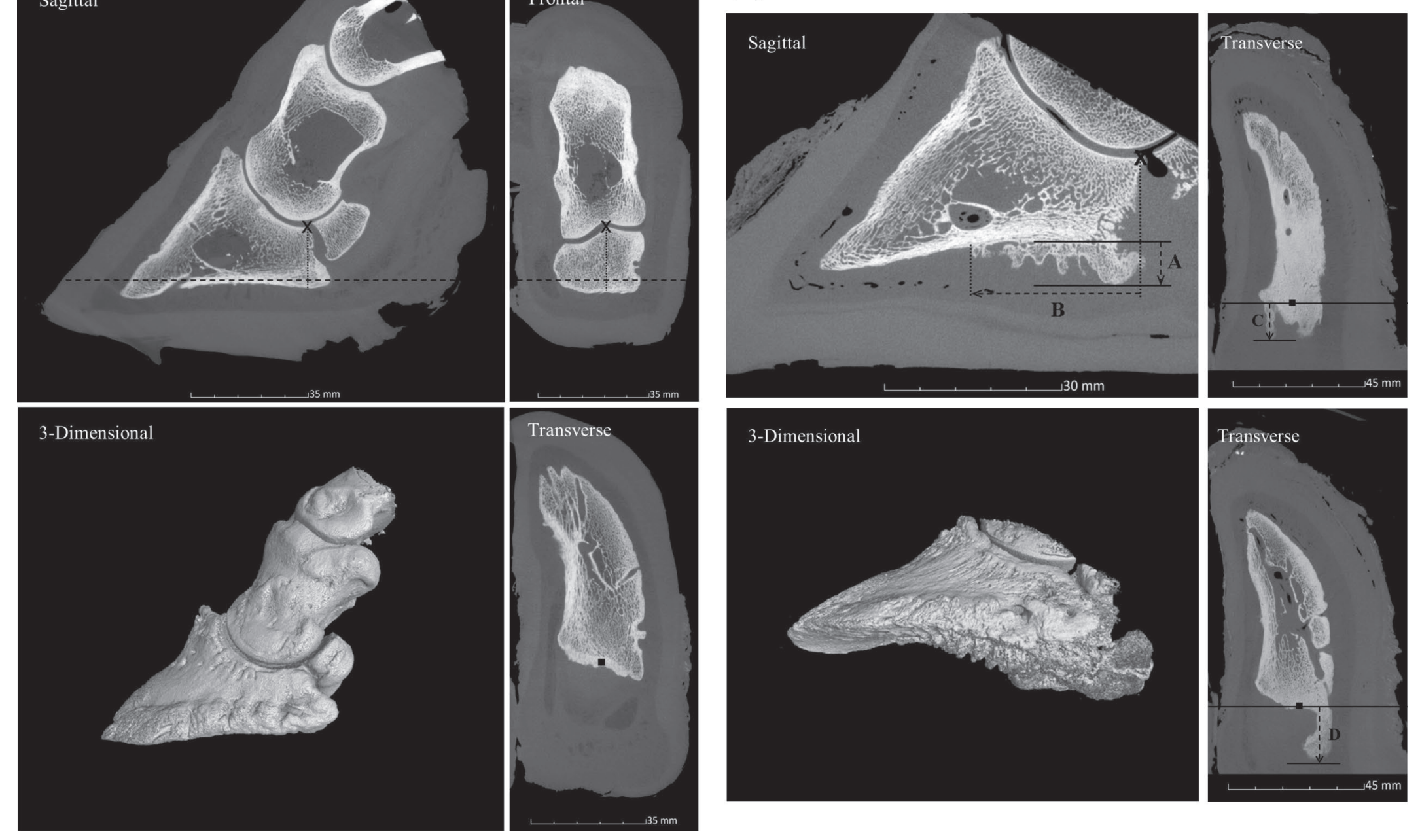

Figure 1. (a) Sagittal, frontal, and transverse cross sectional views of a bovine digit, orientated to take anatomical measurements, and a 3-dimensional image to demonstrate the normal bone contour. The caudal most aspect (identified in the sagittal view) of the trochlear ridge (identified in the frontal view) of the distal interphalangeal joint is located as "X." Dashed lines in the sagittal and frontal sections demonstrate the plane of the transverse image, within which a square dot (- marks the intersection with the dotted line drawn vertically down from X. (b) One sagittal and 2 transverse views of a distal phalanx demonstrating bone development measures A to D, and a 3-dimensional image to demonstrate bone development extending from the caudal aspect of the distal phalanx. Measurement A was the greatest vertical bone development from the contour of the cortical bone, on the plantar aspect of the flexor tuberosity. Site X was a consistent landmark (the caudal-most aspect of the trochlear ridge of the distal phalanx in the distal interphalangeal joint) that did not alter with bone development, and a line drawn vertically down from X was visible in all views and became the origin of measurements B, C, and D. Measurement B was taken in the sagittal plane and extended horizontally to the distal-most tip (toward the toe) of bone development on the plantar aspect of the distal phalanx. Measurements C and $\mathrm{D}$ were taken in the transverse plane and extended to the caudal-most tip of the greatest bone development axial to and abaxial to location X, respectively 
tion score data were available within the period defined for that description of the locomotion score variable. Finally, to test the effect of cows with missing data on model parameters, the locomotion score variable was categorized to allow the inclusion of cows with no locomotion score data within the period defined by the model. The category thresholds specified were "severely lame at $<2 \%$ of locomotion scores," "severely lame at 2 to $50 \%$ of scores" and "severely lame at $>50 \%$ of scores," and a missing data category contained cows where no locomotion score data were available. Other explanatory variables included were age (yr) at slaughter, genetic line, management system, proportion of life spent in each management system, and culling reason. Polynomial terms of all continuous variables were also tested in the models.

Models were constructed in Minitab 17 statistical software (2010; Minitab Inc., State College, PA) following principles outlined by (Dohoo et al., 2009) and took the format

$$
\begin{gathered}
Y_{i}=\beta 0_{i}+\beta^{1} X_{i}^{1}+\beta^{2} X_{i}^{2}+\ldots+e 0_{i}, \\
{\left[e 0_{i}\right] \sim N\left(0, \sigma_{e}^{2}\right),}
\end{gathered}
$$

where $Y_{i}$ was a measurement of bone development on the caudal aspect of the distal phalanx (either BD-Max or BD-Ave in separate models), $X_{i}$ were exposure variables for the $i$ th cow, $\beta$ were the relevant coefficients of these exposures, $\beta 0$ the intercept value, and $e 0_{i}$ the residual error term, with mean 0 and variance $\sigma_{e}^{2}$. Biologically plausible interactions were tested and significant terms were retained in the model at $P<0.05$.

Model fit was assessed as follows. Data points with large leverage or influence were identified and their effects on model parameters were evaluated using the DFITS function in Minitab, which quantifies the difference in model parameters both with and without each data point. Model fit was deemed adequate if model parameters remained biologically and statistically similar (i.e., coefficients remained significant) when the model was refitted excluding data points with high leverage or influence. Both outcome variables were log-transformed to determine whether model fit or interpretation changed with the transformed outcome, but because this did not occur, nontransformed data were used for the final models.

\section{Histological Analysis of Bone Developments}

Samples from the caudal aspects of 9 distal phalanges, identified by a stratified random sampling technique, underwent histology to investigate the tissue architecture and cellular composition. The subset consisted of 3 normal samples, 3 samples with bone development from cows where lameness history was available, and 3 of the most severely affected samples, which were from old cows and lameness history was unavailable.

The samples were cut to $5 \times 10 \times 10 \mathrm{~mm}$ with a band saw and immersed in PBS for $12 \mathrm{~h}$, to wash in preparation for histology. The following histology protocol was optimized using samples from claws not included in the analysis subset but displaying similar changes. Samples were (1) decalcified in Calci-Clear (National Diagnostics, Atlanta, GA), which was replaced every 2 $\mathrm{h}$ until the endpoint of decalcification was reached. The endpoint was identified when no precipitate $\left[\mathrm{Ca}(\mathrm{OH})_{2}\right]$ formed after the addition of ammonium hydroxide to a sample of the Calci-Clear solution, and typically took $28 \mathrm{~h}$. The samples were replaced in Calci-Clear for a further $6 \mathrm{~h}$ beyond the endpoint because, in preliminary work, this had improved cutting without affecting the histology; (2) dehydrated in increasing concentrations of ethanol up to $100 \%$ (in order, $70 \%$ ethanol for 1.5 $\mathrm{h}$ at room temperature; $90 \%$ for $72 \mathrm{~h}$ at $5^{\circ} \mathrm{C} ; 100 \%$ for $3 \mathrm{~h}$ at room temperature $\times 2$ ); (3) cleared with xylene $(3 \mathrm{~h} \times 2)$; (4) embedded in paraffin wax; (5) cut in the sagittal plane at $9 \mu \mathrm{m}$ using a microtome (Leica Microsystems UK Ltd., Milton Keynes, UK) with an "N35" long-duration stainless steel microtome blade (Feather, Osaka, Japan); (6) stained with hematoxylin and eosin: in brief, sections were deparaffinized, rehydrated through an ethanol series, placed into hematoxylin for 2.5 min, immersed in 1\% industrial methylated spirit and $10 \%$ ammoniated water for $15 \mathrm{~s}$ each, and placed in eosin for $4 \mathrm{~min}$ before dehydration through an ethanol series; (7) analyzed and photomicrographs taken using a light microscope (DM5000 B, Leica Microsystems Ltd.) and a Digital Color Camera (DFC420, Leica Microsystems Ltd.) with Leica Application Suite software. Analysis was carried out in a blinded manner to ensure no bias toward samples. Histology and microscopy were supervised by C. S. R. (an anatomist and histologist).

\section{RESULTS}

\section{Animal Data}

Within the sample collection period, 142 hind feet from 72 cows were collected; 2 feet from 2 different cows were irretrievable at the abattoir. Mean cow age at slaughter was 71 mo (median: 69, range: 30 to 139) and reasons cited for culling were grouped as fertility ( $\mathrm{n}$ $=35)$, mastitis $(\mathrm{n}=14)$, lameness $(\mathrm{n}=8)$, and "other" $(\mathrm{n}=15)$. 
Table 1. Descriptive data of bone development measures (in $\mathrm{mm}$ ) at the claw level (A to D) and at the cow-level (BD-Max and BD-Ave), for all cows

\begin{tabular}{|c|c|c|c|c|c|c|c|c|}
\hline Measurement ${ }^{1}$ & Claw & Count & Mean & Minimum & Lower quartile & Median & Upper quartile & Maximum \\
\hline A & Medial & 142 & 0.43 & 0 & 0 & 0 & 0.79 & 4.92 \\
\hline \multirow[t]{2}{*}{$\mathrm{C}$} & Lateral & 142 & 1.41 & 0 & 0 & 0 & 0 & 30.4 \\
\hline & Medial & 142 & 0.29 & 0 & 0 & 0 & 0 & 17.7 \\
\hline $\mathrm{D}$ & Lateral & 141 & 6.47 & 1.31 & 4.01 & 5.14 & 7.39 & 28.2 \\
\hline BD-Ave & & 72 & 12.2 & 2.28 & 4.47 & 6.94 & 12.3 & 69.0 \\
\hline
\end{tabular}

${ }^{1}$ Measurements A and B quantify bone development in the plantar and dorsal directions from the caudal aspect of the distal phalanx of each claw, respectively, and $\mathrm{C}$ and $\mathrm{D}$ describe the length of caudal protrusions on the medial and lateral aspects of the distal phalanx. A to D are combined within claw, and the greatest claw value for each cow (BD-Max) and the average value across the hind claws (BD-Ave) are shown. Lateral $>$ medial when all measurements A to $\mathrm{D}$ were tested together, $P=0.024$. Differences between lateral and medial measurements of $\mathrm{A}$ to D when tested individually were not significant $(P=0.32,0.30,0.07$, and 0.11 , respectively).

\section{Descriptive Statistics}

Table 1 describes data for measurements of bone development A to D for the entire data set of 142 hind feet. The distribution for each measurement was right skewed, and $\mathrm{A}$ to $\mathrm{C}$ measurements had a high count of zero values. Lateral claw measurements were greater than medial when all measurements $\mathrm{A}$ to $\mathrm{D}$ were tested together $(P=0.024)$; however, when each measurement (A, B, C, or D) was tested individually, differences between lateral and medial claw measurement within foot were not significant. Measurements A to $\mathrm{C}$ were $>0$ more frequently in the lateral than the medial claw; poor correlations existed between lateral and medial measurements within foot; and Figure 2 illustrates correlations within individual measurements (A to D) between contralateral claws. Within claw, each measurement A to D was significantly correlated with every other measurement: Spearman rank correlation coefficients $(\rho)$ ranged from 0.98 between A and B to 0.39 between $\mathrm{C}$ and $\mathrm{D}(P<0.001$ in each case $)$.

The claw with the greatest bone development measurement for each cow (which became the variable BDMax for that cow) was a lateral claw in 44 animals and a medial claw in 28 , as follows: right lateral $(\mathrm{n}=22)$, left lateral (22), right medial (20), and left medial (8) claw. The BD-Max and BD-Ave variables were highly correlated $\left(\mathrm{R}^{2}=0.92\right.$; Figure 3$)$ with a cow's BD-Max being, on average, 1.7 times greater than the BD-Ave.

\section{Statistical Modeling}

Locomotion score data were available during the 6 , 12,18 , and 24 mo following first calving for $60,57,58$, and 53 cows, respectively, and during the $6,12,18$, and 24 mo preceding slaughter for $34,38,39$, and 45 cows. Of the 72 cows, 28 were recorded as having been treated for a CHDL at some point during life.

All final models were based on the 38 cows that had locomotion score data available during the 12 mo preceding slaughter. These models (a, b, and c) are presented in Table 2 and include the explanatory variables age and either the percentage of locomotion scores at which a cow was lame during the 12 mo preceding slaughter (models a and b) or the occurrence of CHDL during life (model c) for each outcome measure (BDMax and BD-Ave). Locomotion score variables were significant when they described the percentage of lame scores between $2(\mathrm{n}=24$ cows $)$ and $12(\mathrm{n}=38$, Table 2$)$ mo preslaughter. Model parameters did not differ substantively when the locomotion score variable included data from different periods before slaughter; model (a) in Table 2 is an example of a model with good fit that was based on more of the data. This model estimates that a cow that had been scored lame at all locomotion scores during the 12 mo preslaughter would have had a BD-Max of $9.72 \mathrm{~mm}$ (SE $4.75 \mathrm{~mm}$ ) greater than a cow that was sound at all locomotion scores (Table 2); the effect of locomotion on BD-Ave was not significant $(P=0.08)$. These 38 cows had a mean age of 60 mo (range: 31 to $85 \mathrm{mo}$ ) and were lame at $20 \%$ (range: 0 to $93 \%$ ) of locomotion scores within the 12 mo preceding slaughter; mean age of the remaining cows was 83 mo.

Model (b) in Table 2 contains the explanatory variables age and categories of the locomotion score variable; categorizing the locomotion score variable enabled the effect of cows with missing data on model parameters to be tested. As cows with missing data were introduced into these categories, the number of outcome data points increased although there were no new explanatory data. The effect sizes and standard errors remained similar, although model fit deteriorated 
and ultimately prevented the model from converging. The models with the best fit have been reported and contain no cows with missing data. Model (b) estimates that cows that had been lame at $>50 \%$ of locomotion scores had BD-Max and BD-Ave $9.83 \mathrm{~mm}$ (SE 3.92) and $5.00 \mathrm{~mm}$ (SE 2.36) greater than cows that had
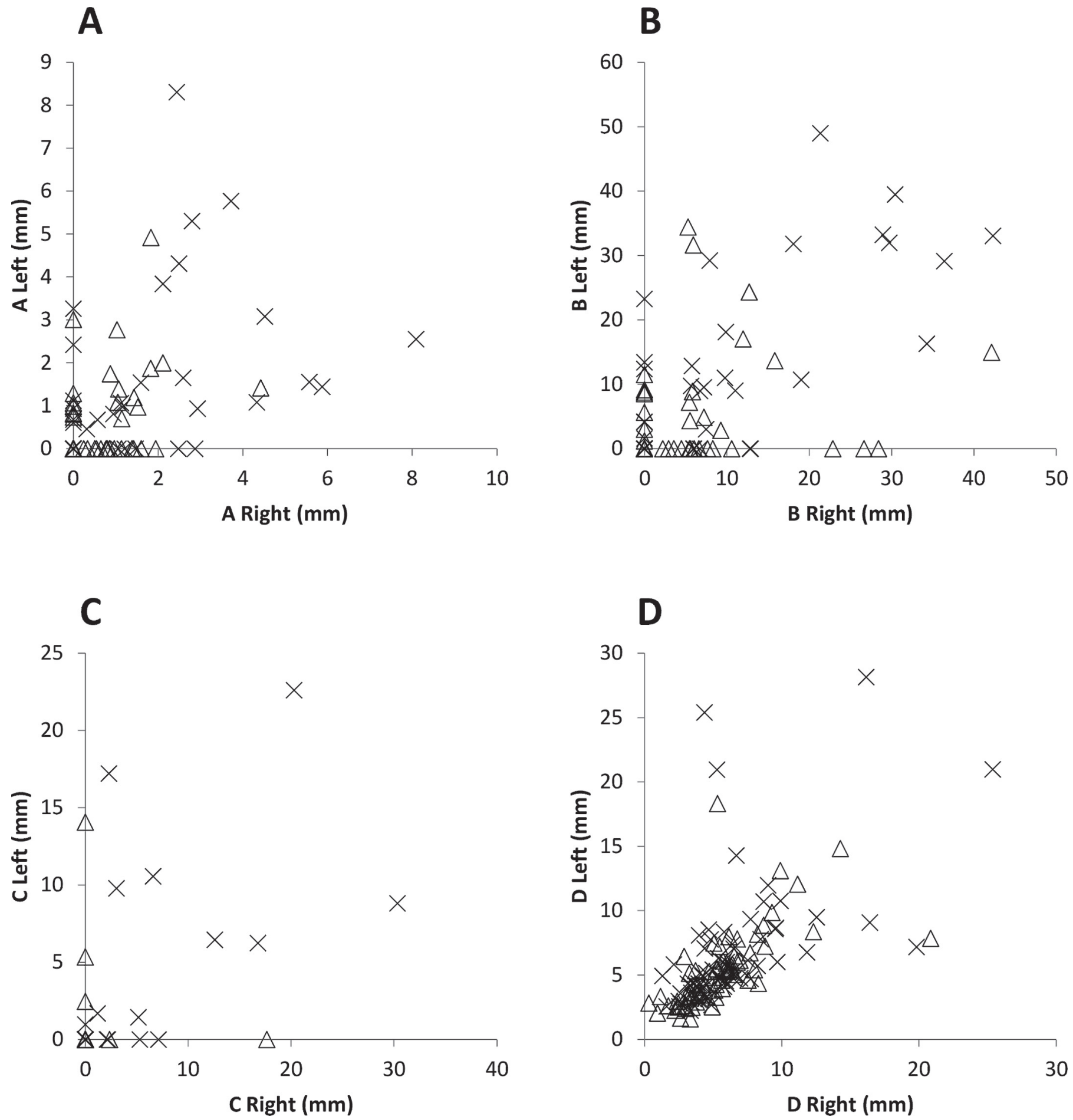

Figure 2. Scatterplots of 4 measures of bone development, A to D, from lateral $(\times)$ and medial $(\Delta)$ claws, between contralateral hind feet within cow, from a postmortem study investigating the association between bone development on the caudal aspect of the distal phalanx bone and lameness history. 


\section{BD-Ave vs BD-Max}

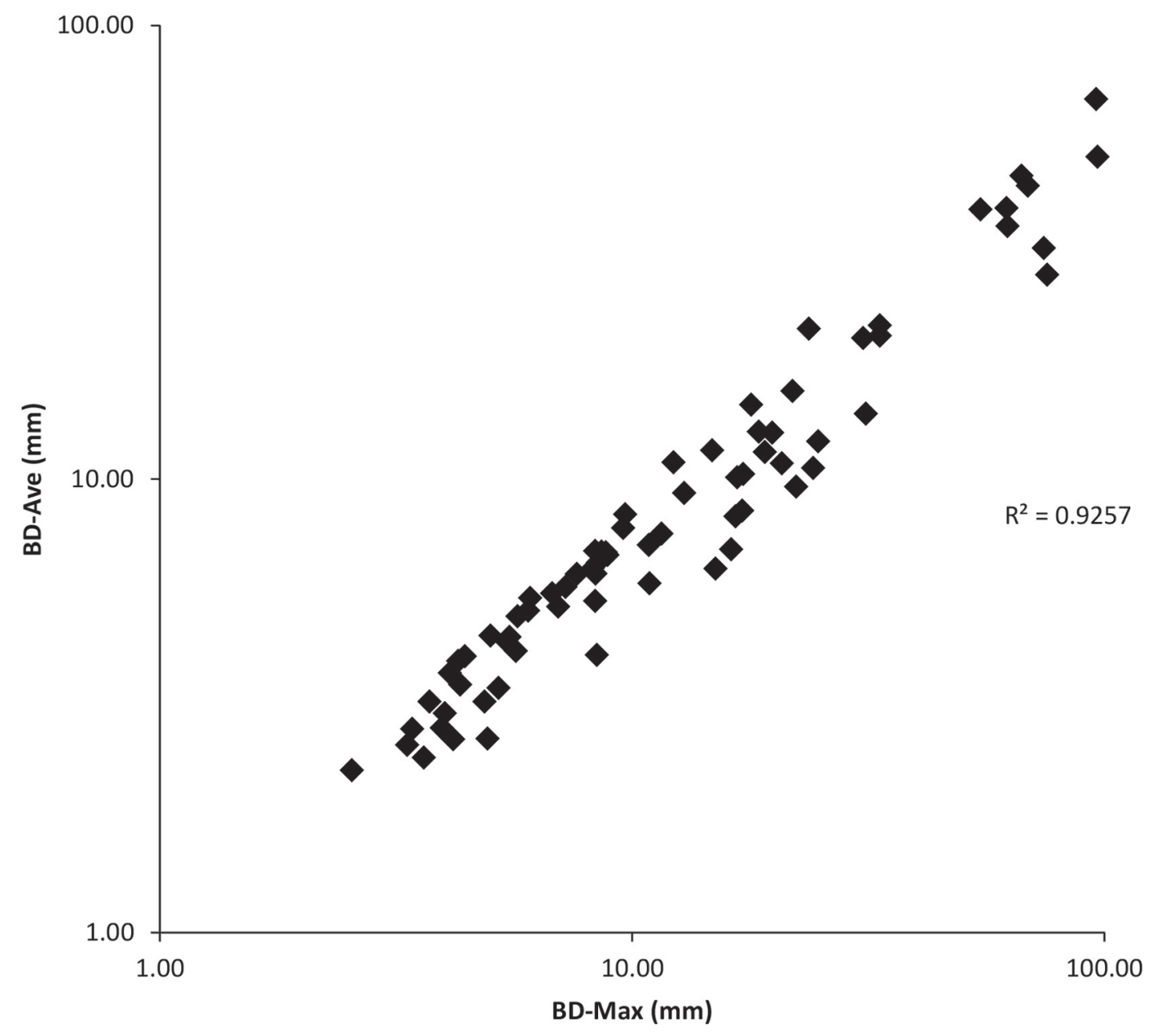

Figure 3. Scatterplot showing the correlation between 2 cow-level measures that describe the average length and the maximum length of bone development on the caudal aspect of the distal phalanges of the hind feet (BD-Ave and BD-Max, respectively), in a postmortem study investigating the link between bone development at slaughter and lameness history.

been lame at $<2 \%$ of scores, respectively (Table 2 ). Cows that had been lame at between 2 and $50 \%$ of scores had a smaller but nonsignificant effect in the same direction.

Model (c) in Table 2 contained CHDL occurrence as an explanatory variable, which was based on the same 38 cows as the previous models. Both BD-Max and BD-Ave were greater in cows that had experienced a CHDL compared with those who had not, regardless of the period from which data were taken. In model (c), the 12 cows that had received treatment for a CHDL had a BD-Max value $6.98 \mathrm{~mm}$ (SE 2.17) greater than the 26 cows that had not; the effect size for BD-Ave was $3.55 \mathrm{~mm}$ (SE 1.33).

In all models, age explained the majority of the variation in bone development; polynomial terms of age were not significant in the final models. Both locomotion and CHDL occurrence explained additional variation in bone development. Because an increasing percentage of locomotion scores of lame cows was positively associated with occurrence of CHDL (Figure 4), neither variable was included in the same final models.

Locomotion score variables describing lameness in periods subsequent to first calving or during first or second lactation did not significantly predict bone development at slaughter. Culling reason, genetic line, and management system were not significant in the models nor was occurrence of infectious causes of lameness. Height and width of the flexor tuberosity, variables describing locomotion score data early in life, and mean and median locomotion scores for various periods throughout life were all nonsignificant. 
Table 2. Linear regression models based on 38 cows with locomotion score data within the 12 mo preceding slaughter, with outcome variables BD-Max (the sum of bone development measures A to D on the most severely affected hind claw, for each cow) and BD-Ave (the average of the sum of bone development measures on each hind claw of each cow)

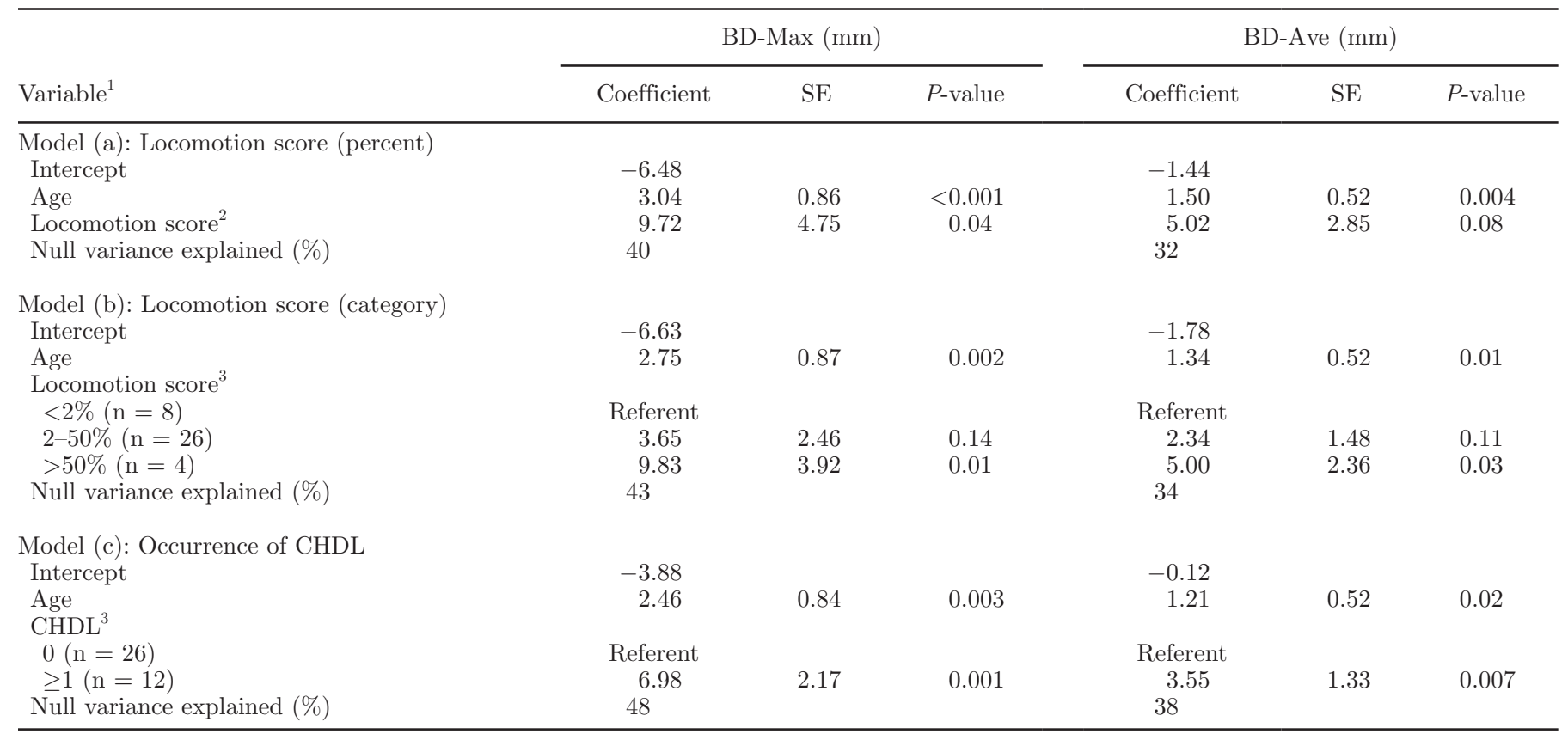

${ }^{1}$ Explanatory variables were age at slaughter (yr) and (a) locomotion score as the percentage of scores at which a cow was severely lame (locomotion score 4 or 5) during the 12 mo preceding slaughter; (b) locomotion score as described in (a) but categorized as severely lame at $<2 \%$ of scores, at $2-50 \%$ of scores, or at $>50 \%$ of scores; or (c) occurrence of claw horn disruption lesions (CHDL) throughout life $(0$ or $\geq 1)$.

${ }^{2}$ The coefficient demonstrates the difference between 0 and $100 \%$ of scores lame.

${ }^{3}$ Numbers of cows in each category are shown in parentheses. Categories were used during modeling to allow the inclusion of all cows with missing locomotion or lesion data. Models did not fit when all cows with missing data were included in these categories. Therefore, models with good fit are reported, rather than models with inadequate fit that include missing data.

\section{Histology of Bone Developments}

On visual inspection of the morphology, all samples resembled bone. Histologically, all abnormal bone growth samples $(\mathrm{n}=6)$ resembled benign growth of bone with a periosteal lining, from the surface of a bone (Figure 5), in concordance with the structure of osteoma, or exostosis. Cortical bone surrounded trabecular bone, lined externally with periosteum and internally with endosteum. In some samples in the abnormal bone growth groups, the periosteum appeared thickened, constituting a thick fibrous area peripheral to the cortical bone, densely populated with cells on the superficial border. In some samples where bone extended far caudally, some bone segments were not connected to neighboring bone but were surrounded by the soft tissue of the heel bulb.

\section{DISCUSSION}

Histologically, the tissue we studied was bone, and this work suggests that it can be termed osteoma or exostosis. This is the first study to demonstrate that bone development on the caudal aspect of the distal phalanx at slaughter is positively associated with lameness history: after accounting for the effect of age, cows that had experienced more lameness in the 12 mo before slaughter had greater bone development. Lifetime occurrence of CHDL was associated with bone development, whereas the occurrence of infectious lameness diseases was not; this data set suggests that the bone development is specific to CHDL. Significant locomotion score terms detailed the percentage of locomotion scores at which a cow was severely lame (score 4 or 5 ) leading up to slaughter, suggesting that bone development is associated with chronic lameness. The model indicates that BD-Max would be $9.7 \mathrm{~mm}$ greater if a cow had been lame at all locomotion scores in the 12 mo preceding slaughter than if the cow had been sound at all scores.

Age explained much of the variation in bone development, as previously reported on the distal phalanges of cattle (Tsuka et al., 2012) and at several anatomical locations in humans (Benjamin et al., 2006; Slobodin et al., 2007). Further, bone developments were greater on the lateral claw, which bears more weight (van der Tol 
et al., 2004). This study reports an additional effect of lameness from CHDL to the effect of age. Extrapolation of the reported models to a greater age range (outside the 31 to 85 mo tested) would be inappropriate, yet we believe that the general inferences regarding the effect of lameness on bone development are also likely to be observed in older cows.

Recent work suggests that early detection and treatment of clinical lameness cases is a key aspect of managing the disease (Bell et al., 2009; Green et al., 2014; Groenevelt et al., 2014). The digital cushion sits beneath the caudal aspect of the distal phalanx and its capacity to dissipate shock during foot-strike may be important in preventing CHDL (Räber et al., 2004; Bicalho et al., 2009; Machado et al., 2011). The inflammatory response to active CHDL could damage these cushioning structures and utilize local fat reserves (Räber et al., 2006). To stimulate discussion around the poorly defined sequence of events during lameness onset and perpetuation, we propose a possible pathogenic pathway that is outlined in Figure 6, and as follows: (1) inflammation occurs during an active CHDL, (2) fat is utilized locally, (3) the digital cushion becomes depleted or is replaced with scar tissue and

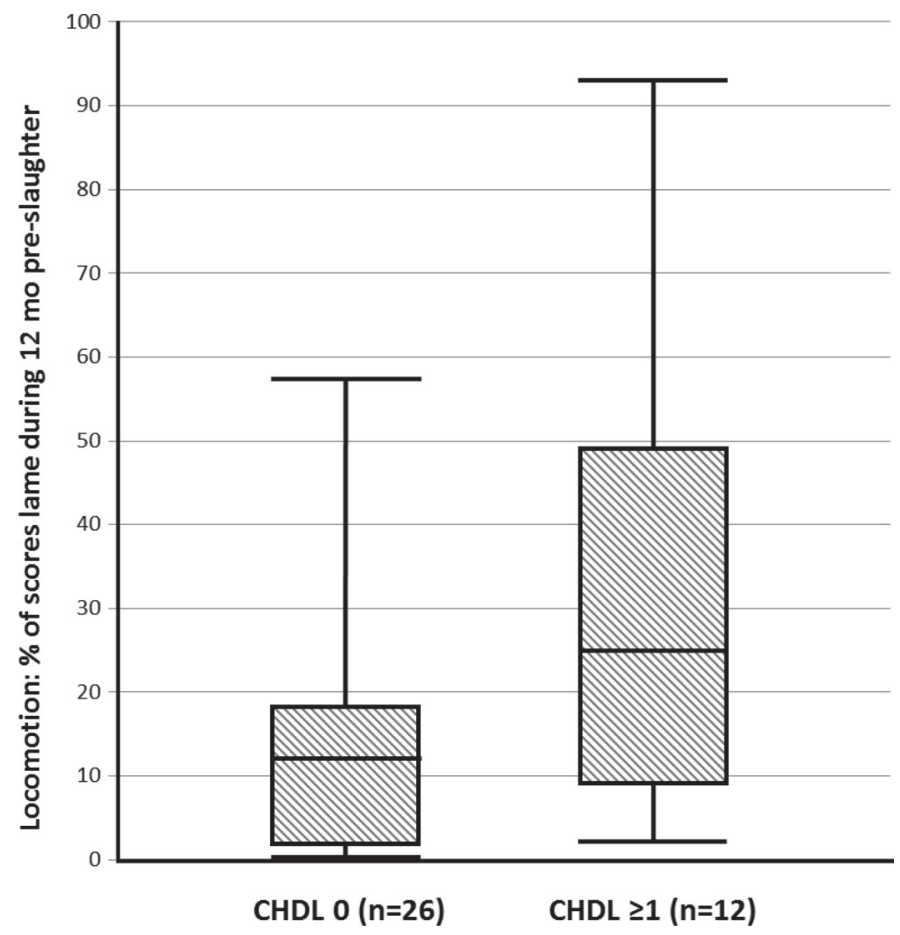

Figure 4. Distribution of the explanatory variable locomotion (the percentage of scores at which a cow was lame during the 12 mo preslaughter) within 2 groups of cows that had not (CHDL 0) and that had (CHDL $\geq 1$ ) been recorded as having a claw horn disruption lesion during life. Box plot shows minimum and maximum values, interquartile range (25th and 75 th percentiles), and median value. future cushioning capacity is impeded, (4) both local inflammation and trauma to the periosteum stimulate bone development, which exerts greater point-forces on the sole-producing germinal epithelium of the foot, and (5) a self-perpetuating cycle begins, whereby a CHDL damages the foot and predisposes the cow to further lameness, and consigns the cow to a lifetime at greater risk of lameness. In a recent randomized controlled trial testing 4 treatments for CHDL, Thomas et al. (2015) found that administering nonsteroidal antiinflammatory treatment together with applying a block to the nonlame claw produced the best recovery rates. Both reducing inflammation and weight bearing on the sole appear to be important in promoting the healing and resolution of lameness due to CHDL. Further work is required to confirm or refute other aspects of this pathway.

Bone developments varied in appearance: some were smaller and consisted of mostly dense bone, whereas others were larger and contained more trabecular bone; these presentations may reflect 2 different pathological processes. Where bone development was small, it consisted of dense cortical bone extending from the enthesis into the deep digital flexor tendon. Such development can occur through physiological remodeling of the tendon insertion to increase the surface area of attachment for strength (Shaibani et al., 1993; Benjamin et al., 2000). Larger bone developments were not limited to the enthesis and resembled exostosis. This is likely stimulated by trauma to the osteoprogenitor cells of the periosteum, which respond by multiplying and differentiating into osteoblasts to form new bone (Rana et al., 2009). This "periosteal reaction" could be stimulated by direct trauma due to insufficiencies in the force-dissipating structures surrounding the flexor tuberosity (Benjamin et al., 2006) or through macrophage action in surrounding tissues, such as inflammation during an active CHDL (Hasturk et al., 2012). The latter mechanisms suggest that a CHDL precedes bone development and could highlight the importance of nonsteroidal antiinflammatory therapy in treating CHDL, although a temporal link between lameness and bone development cannot be confirmed from this study.

Although the work described here seems most pertinent to the etiology of sole ulcer and sole hemorrhage, it could also help explain, in part, the etiology of other lesions such as white line disease and heel ulcers. White line disease may result from compression of the germinal epithelium when compression occurs beneath the abaxial aspect of the flexor tuberosity (Lischer et al., 2002) and may have a similar causal pathway to sole ulcers and hemorrhage. This study and other crosssectional work (Tsuka et al., 2012) suggest that bone development initially occurs on the abaxial aspect of 

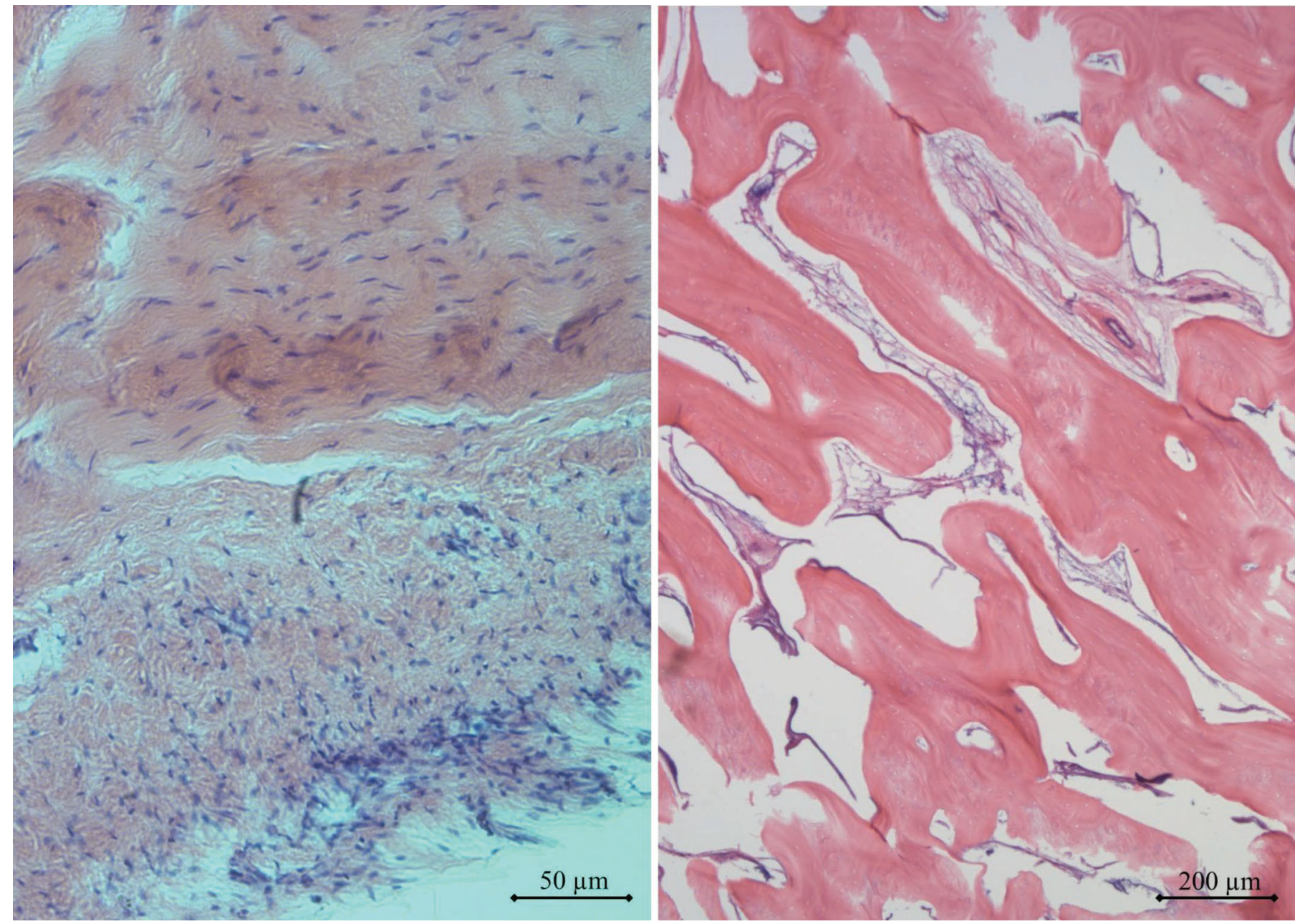

Figure 5. Histology of new bone developments on the caudal aspect of the distal phalanx confirms that they are bone. The image on the left shows bone development growing vertically down from the flexor tuberosity. Toward the top of the image, normal cortical bone of the flexor tuberosity is visible. Toward the bottom, the periosteum appears as a thickened fibrous structure with increased cellularity on the peripheral border, showing active periosteocytes in a response to trauma. The image on the right appears to be normal trabecular bone but is from the center of a large bone development outside the contour of the normal bone, demonstrating structured new bone growth in this location. Color version available online.

the distal phalanx. Hemorrhage in the corium beneath this site could elicit or be exacerbated by bone development on the abaxial aspect of the distal phalanx, and be visible in the white line as it grows out, becoming a risk area for separation, impaction, and infection. This could explain why CHDL occur around similar stages of lactation and share similar risk factors (Leach et al., 1997; Machado et al., 2011; Green et al., 2014), pointing to a common underlying disease process.

Heel ulcers have been described as being related to but distinct from sole ulcers; they occur more caudally than the typical sole ulcer site, appear more prevalent in older animals, and recover poorly in comparison (Toussaint-Raven, 1985; Blowey et al., 2000; Haslam and Roberts, 2011). We observed extensive bone development caudal to the distal phalanx, which extended up to $28.2 \mathrm{~mm}$; the caudal limit of large bone development corresponded with the heel ulcer site. We propose that during foot-strike, the tips of these caudal bone developments could exert focal pressure on the germinal epithelium in this region, causing contusions that develop into heel ulcers. Further work is required to confirm or refute this mechanism.

This study was based on a convenience sample of the hind feet from 72 Holstein dairy cows culled from one UK research herd. Because locomotion score data were incomplete for cows that had moved from Langhill to the Acrehead unit, our model criteria might have led to the selection of a biased subset(s) of the study population. The first lameness variable constructed described locomotion during the first 2 lactations. The sample size was up to 60 cows (depending on the data available 
within the period tested) and we found no association between locomotion during the first and second lactations and bone development. However, in this instance, the period of locomotion data and slaughter were separated by up to $8 \mathrm{yr}$, and the lack of an association was not surprising. Next, the locomotion variable described the period immediately preceding slaughter; animals were only eligible for these models if they had locomotion data during the 12 mo preceding slaughter. As locomotion data were collected only at the Langhill unit, the cohort was not a randomly selected subset of the population; rather, it was a specific cohort constituting younger cows. Cows did not remain at Langhill beyond 4 lactations but could be moved to Acrehead early, largely due to incidence of mastitis, poor fertil- ity, or specific experimental protocols. Although we acknowledge the potential for bias, we have no reason to suspect that early movement of cows to Acrehead influenced our results because the reasons for movement were not directly associated with lameness. Associations were evident and statistically significant in our final models and it is certainly possible that the general inferences reported apply to the wider population of Holstein dairy cows in any lactation, not selected for culling.

In summary, for bias to undermine the central inferences of our results and make them ungeneralizable to the wider population, either the association would need to be specific to the subpopulation studied or the converse of the results would need to be true in the wider

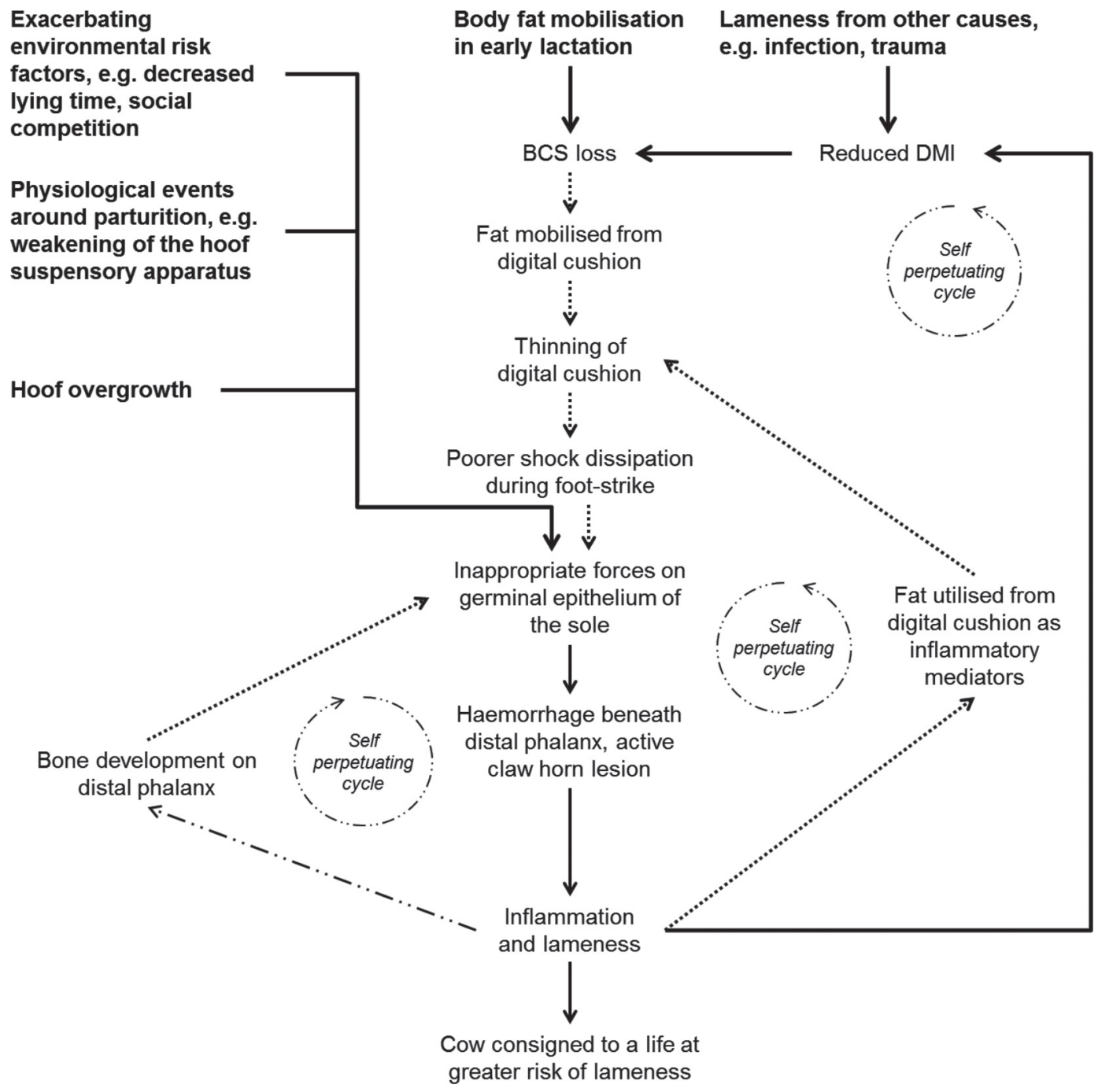

Figure 6. Proposed sequences of events involved in the pathogenesis of claw horn disruption lesions (CHDL). Self-perpetuating cycles are suggested, with inflammation being a key factor in lesion recurrence. Line styles highlight the levels of current evidence supporting the links displayed: (1) data in peer-reviewed literature supports this link (solid line), (2) some evidence exists to substantiate this link, but it has not been confirmed (dotted line), and (3) the present study hypothesizes this link (dashed-dotted). 
population; that is, older cows with bone development had better locomotion. We think this unlikely given the previous supporting work in this area (Tsuka et al., 2012) and the biological plausibility of our findings: CHDL occurrence was positively associated with bone development [model (c), Table 2] and the percentage of lame locomotion scores preceding slaughter was positively associated with CHDL occurrence (Figure 4). This suggests that an association between lameness measured by locomotion score and bone development is plausible. Further studies, either imaging the distal phalanx during life or prospectively culling randomly selected cows from a herd, are required to confirm or refute our inferences about the generalizability of our results to the wider population.

Approximately $60 \%$ of the variation in bone development remained unexplained, depending on the model, and explanatory variables in the statistical models may have been either missed or imprecise. For example, locomotion scoring is known to have relatively poor inter- and intra-observer repeatability (Whay et al., 1997; Channon et al., 2009; Walker et al., 2010) but this is improved by aggregating scores on the 5-point scale to binary "lame" and "nonlame" classifications, as we did. If other important variables for our models exist, they were unavailable for analysis. The variables genetic line, management system, and culling reason were nonsignificant, although, given the small data set, their effect could have gone undetected while still being important in the wider population.

\section{CONCLUSIONS}

This work describes and quantifies bone development, or exostosis, on the distal phalanx of cull dairy cows. Where locomotion data were available, bone development was greater in cows with a history of lameness from lesions of claw horn disruption (as indicated by locomotion score and lesion occurrence) after accounting for the effect of age.

\section{ACKNOWLEDGMENTS}

This work was funded by the Agriculture and Horticulture Development Board (AHDB; Kenilworth, UK) Dairy Division, a levy board, not-for-profit organization working on behalf of British Dairy Farmers. The authors thank staff at the Hounsfield Facility (University of Nottingham) for advice on CT scanning, and staff at the SRUC Dairy Research Centre (Edinburgh, UK), Dave Roberts and Maggie March, for their help accessing data. The Hounsfield Facility received funding from ERC (FUTUREROOTS; Brussels, Belgium),
BBSRC (Swindon, UK), and The Wolfson Foundation (London, UK), and SRUC received financial support from the Scottish Government (Edinburgh, UK).

\section{REFERENCES}

Algers, B., G. Bertoni, D. Broom, J. Hartung, L. Lidfors, J. Metz, L. Munksgaard, T. Nunes Pina, P. Oltenacu, J. Rehage, and J. Rushen. 2009. Scientific report of EFSA prepared by the Animal Health and Animal Welfare Unit on the effects of farming systems on dairy cow welfare and disease. EFSA J. (Annex) 1143:137-151.

Archer, S. C., R. Newsome, H. Dibble, C. J. Sturrock, M. G. G. Chagunda, C. S. Mason, and J. N. Huxley. 2015. Claw length recommendations for dairy cow foot trimming. Vet. Rec. http://dx.doi. org/10.1136/vr.103197.

Bell, N. J., M. J. Bell, T. G. Knowles, H. R. Whay, D. J. Main, and A. J. F. Webster. 2009. The development, implementation and testing of a lameness control programme based on HACCP principles and designed for heifers on dairy farms. Vet. J. 180:178-188. http:// dx.doi.org/10.1016/j.tvjl.2008.05.020.

Benjamin, M., A. Rufai, and J. R. Ralphs. 2000. The mechanism of formation of bony spurs (enthesophytes) in the Achilles tendon. Arthritis Rheum. 43:576-583. http://dx.doi.org/10.1002/15290131(200003)43:3<576:AID-ANR14>3.0.CO;2-A.

Benjamin, M., H. Toumi, J. R. Ralphs, G. Bydder, T. M. Best, and S. Milz. 2006. Where tendons and ligaments meet bone: Attachment sites ('entheses') in relation to exercise and/or mechanical load. J. Anat. 208:471-490. http://dx.doi.org/10.1111/j.14697580.2006.00540.x.

Bicalho, R. C., V. S. Machado, and L. S. Caixeta. 2009. Lameness in dairy cattle: A debilitating disease or a disease of debilitated cattle? A cross-sectional study of lameness prevalence and thickness of the digital cushion. J. Dairy Sci. 92:3175-3184. http://dx.doi. org/10.3168/jds.2008-1827.

Bicalho, R. C., and G. Oikonomou. 2013. Control and prevention of lameness associated with claw lesions in dairy cows. Livest. Sci. 156:96-105. http://dx.doi.org/10.1016/j.livsci.2013.06.007.

Blowey, R. W., P. Ossent, C. L. Watson, V. Hedges, L. E. Green, and A. J. Packington. 2000. Possible distinction between sole ulcers and heel ulcers as a cause of bovine lameness. Vet. Rec. 147:110-112.

Chagunda, M. G. G., D. M. Römer, and D. J. Roberts. 2009. Effect of genotype and feeding regime on enteric methane, non-milk nitrogen and performance of dairy cows during the winter feeding period. Livest. Sci. 122:323-332. http://dx.doi.org/10.1016/j. livsci.2008.09.020.

Channon, A. J., A. M. Walker, T. Pfau, I. M. Sheldon, and A. M. Wilson. 2009. Variability of Manson and Leaver locomotion scores assigned to dairy cows by different observers. Vet. Rec. 164:388-392.

Dohoo, I. R., W. Martin, and H. Stryhn. 2009. Model-building strategies. Pages 365-394 in Veterinary Epidemiologic Research. 2nd ed. M. McPike, ed. VER Inc., Charlottetown, Canada.

Dyer, R. M., N. K. Neerchal, U. Tasch, Y. Wu, P. Dyer, and P. G. Rajkondawar. 2007. Objective determination of claw pain and its relationship to limb locomotion score in dairy cattle. J. Dairy Sci. 90:4592-4602. http://dx.doi.org/10.3168/jds.2007-0006.

Enevoldsen, C., Y. T. Grohn, and I. Thysen. 1991. Sole ulcers in dairy cattle-Associations with season, cow characteristics, disease, and production. J. Dairy Sci. 74:1284-1298.

Foditsch, C., G. Oikonomou, V. S. Machado, M. L. Bicalho, E. K. Ganda, S. F. Lima, R. Rossi, B. L. Ribeiro, A. Kussler, and R. C. Bicalho. 2016. Lameness prevalence and risk factors in large dairy farms in upstate New York. Model development for the prediction of claw horn disruption lesions. PLoS ONE 11:e0146718. http:// dx.doi.org/10.1371/journal.pone.0146718.

Gard, J. A., D. R. Taylor, D. R. Wilhite, S. P. Rodning, M. L. Schnuelle, R. K. Sanders, R. J. Beyers, M. A. Edmondson, F. J. Degraves, and E. Van Santen. 2015. Effect of exercise and environmental terrain on development of the digital cushion and bony 
structures of the bovine foot. Am. J. Vet. Res. 76:246-252. http:// dx.doi.org/10.2460/ajvr.76.3.246.

Green, L. E., J. N. Huxley, C. Banks, and M. J. Green. 2014. Temporal associations between low body condition, lameness and milk yield in a UK dairy herd. Prev. Vet. Med. 113:63-71. http://dx.doi. org/10.1016/j.prevetmed.2013.10.009.

Groenevelt, M., D. C. J. Main, D. Tisdall, T. G. Knowles, and N. J. Bell. 2014. Measuring the response to therapeutic foot trimming in dairy cows with fortnightly lameness scoring. Vet. J. 201:283-288. http://dx.doi.org/10.1016/j.tvjl.2014.05.017.

Haslam, M., and J. Roberts. 2011. Sole and heel ulcers-What's the difference? Pages 57-58 in Proc. Cattle Lameness Conf., Sutton Bonington, UK. B. Pocknee, ed. University of Nottingham, Sutton Bonington, UK.

Hasturk, H., A. Kantarci, and T. E. Van Dyke. 2012. Oral inflammatory diseases and systemic inflammation: Role of the macrophage. Front. Immunol. 3:118 http://dx.doi.org/10.3389/fimmu.2012.00118.

Leach, K. A., D. N. Logue, S. A. Kempson, J. E. Offer, H. E. Ternent, and J. M. Randall. 1997. Claw lesions in dairy cattle: Development of sole and white line haemorrhages during the first lactation. Vet. J. 154:215-225.

Lischer, C. J., P. Ossent, M. Räber, and H. Geyer. 2002. Suspensory structures and supporting tissues of the third phalanx of cows and their relevance to the development of typical sole ulcers (Rusterholz ulcers). Vet. Rec. 151:694-698.

Machado, V. S., L. S. Caixeta, and R. C. Bicalho. 2011. Use of data collected at cessation of lactation to predict incidence of sole ulcers and white line disease during the subsequent lactation in dairy cows. Am. J. Vet. Res. 72:1338-1343. http://dx.doi.org/10.2460/ ajvr.72.10.1338.

Maclean, C. W. 1970. A post-mortem X-ray study of laminitis in barley beef animals. Vet. Rec. 86:457-462.

Manson, F. J., and J. D. Leaver. 1988. The influence of concentrate amount on locomotion and clinical lameness in dairy cattle. Anim. Prod. 47:185-190.

Offer, J. E., K. A. Leach, S. Brocklehurst, and D. N. Logue. 2003. Effect of forage type on claw horn lesion development in dairy heifers. Vet. J. 165:221-227. http://dx.doi.org/10.1016/s10900233(02)00171-5.

Potterton, S. L., N. J. Bell, H. R. Whay, E. A. Berry, O. C. Atkinson, R. S. Dean, D. C. Main, and J. N. Huxley. 2012. A descriptive review of the peer and non-peer reviewed literature on the treatment and prevention of foot lameness in cattle published between 2000 and 2011. Vet. J. 193:612-616. http://dx.doi.org/10.1016/j. tvjl.2012.06.040.

Pryce, J. E., B. L. Nielsen, R. F. Veerkamp, and G. Simm. 1999. Genotype and feeding system effects and interactions for health and fertility traits in dairy cattle. Livest. Prod. Sci. 57:193-201.

Räber, M., C. J. Lischer, H. Geyer, and P. Ossent. 2004. The bovine digital cushion-A descriptive anatomical study. Vet. J. 167:258264 .
Räber, M., M. R. L. Scheeder, P. Ossent, C. J. Lischer, and H. Geyer. 2006. The content and composition of lipids in the digital cushion of the bovine claw with respect to age and location-A preliminary report. Vet. J. 172:173-177.

Rana, R. S., J. S. Wu, and R. L. Eisenberg. 2009. Periosteal reaction. AJR Am. J. Roentgenol. 193:W259-W272. http://dx.doi. org/10.2214/AJR.09.3300.

Randall, L. V., M. J. Green, M. G. G. Chagunda, C. Mason, S. C. Archer, L. E. Green, and J. N. Huxley. 2015. Low body condition predisposes cattle to lameness: An 8-year study of one dairy herd. J. Dairy Sci. 98:3766-3777. http://dx.doi.org/10.3168/jds.2014-8863.

Rusterholz, A. 1920. Das spezifisch-traumatische Klauen-sohlengeschwür des Rindes (The specific traumatic sole ulcer of claws in cattle). Schweiz. Arch. Tierheilkd. 62:421-466. [In German]

Sanders, A. H., J. K. Shearer, and A. De Vries. 2009. Seasonal incidence of lameness and risk factors associated with thin soles, white line disease, ulcers, and sole punctures in dairy cattle. J. Dairy Sci. 92:3165-3174. http://dx.doi.org/10.3168/jds.2008-1799.

Shaibani, A., R. Workman, and B. M. Rothschild. 1993. The significance of enthesopathy as a skeletal phenomenon. Clin. Exp. Rheumatol. 11:399-403.

Slobodin, G., M. Rozenbaum, N. Boulman, and I. Rosner. 2007. Varied presentations of enthesopathy. Semin. Arthritis Rheum. 37:119-126. http://dx.doi.org/10.1016/j.semarthrit.2007.01.004.

Sprecher, D. J., D. E. Hostetler, and J. B. Kaneene. 1997. A lameness scoring system that uses posture and gait to predict dairy cattle reproductive performance. Theriogenology 47:1179-1187.

Thomas, H. J., G. G. Miguel-Pacheco, N. J. Bollard, S. C. Archer, N. J. Bell, C. Mason, O. J. R. Maxwell, J. G. Remnant, P. Sleeman, H. R. Whay, and J. N. Huxley. 2015. Evaluation of treatments for claw horn lesions in dairy cows in a randomized controlled trial. J. Dairy Sci. 98:4477-4486. http://dx.doi.org/10.3168/jds.2014-8982.

Toussaint-Raven, E. 1985. Cattle Footcare and Claw Trimming. Farming Press Ltd., Ipswich, UK.

Tsuka, T., K. Ooshita, A. Sugiyama, T. Osaki, Y. Okamoto, S. Minami, and T. Imagawa. 2012. Quantitative evaluation of bone development of the distal phalanx of the cow hind limb using computed tomography. J. Dairy Sci. 95:127-138. http://dx.doi.org/10.3168/ jds.2011-4316.

van Der Tol, P. P. J., S. S. Van Der Beek, J. H. M. Metz, E. N. Noordhuizen-Stassen, W. Back, C. R. Braam, and W. A. Weijs. 2004. The effect of preventive trimming on weight bearing and force balance on the claws of dairy cattle. J. Dairy Sci. 87:1732-1738.

Walker, A. M., T. Pfau, A. Channon, and A. Wilson. 2010. Assessment of dairy cow locomotion in a commercial farm setting: The effects of walking speed on ground reaction forces and temporal and linear stride characteristics. Res. Vet. Sci. 88:179-187. http://dx.doi. org/10.1016/j.rvsc.2009.05.016.

Whay, H. R., A. E. Waterman, and A. J. F. Webster. 1997. Associations between locomotion, claw lesions and nociceptive threshold in dairy heifers during the peri-partum period. Vet. J. 154:155-161. 